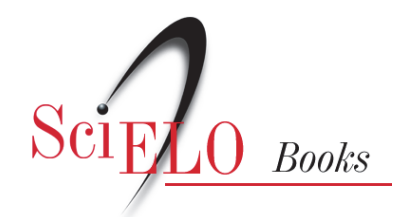

\title{
Lugar do diabo é no inferno de Dante
}

\author{
Teresa Arrigoni
}

FERRAZ, S., et al.,orgs. Deuses em poéticas: estudos de literatura e teologia [online]. Belém: UEPA; Campina Grande: EDUEPB, 2008. 364 p. ISBN 978-85-7879-010-3. Available from SciELO Books $<\underline{\text { http://books.scielo.org }>\text {. }}$

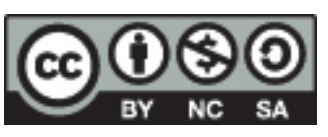

All the contents of this work, except where otherwise noted, is licensed under a Creative Commons Attribution-Non Commercial-ShareAlike 3.0 Unported.

Todo o conteúdo deste trabalho, exceto quando houver ressalva, é publicado sob a licença Creative Commons Atribuição Uso Não Comercial - Partilha nos Mesmos Termos 3.0 Não adaptada.

Todo el contenido de esta obra, excepto donde se indique lo contrario, está bajo licencia de la licencia Creative Commons Reconocimento-NoComercial-CompartirIgual 3.0 Unported. 


\section{Lugar do Diabo é no Infer- no de Dante}

Teresa Arrigoni 


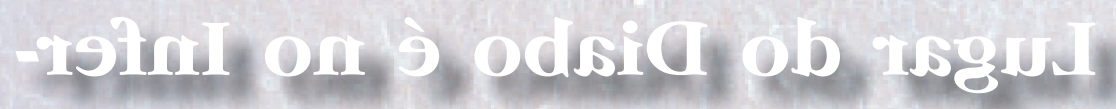
sjmiscrsb on

jMrogintA De979T 
ARRIGONI, Maria Teresa
Tutti gli dei delle nazioni sono un nulla

(Salmi, 96,5)

Un mostro bestiale, irsuto e deforme, con gli occhi di fuoco e

la bocca drighignante

(Papini, 309)

O demônio na rua, no meio do redemunho

(Rosa, 77)

Segundo Cousté, em sua Biografia do Diabo, o próprio pode ter vários nomes, dentre os quais destaca: "Diabo (de origem grega e significa acusador, caluniador), Satã (de tradição hebréia, que equivale a inimigo, adversário)" e mais adiante 'Demônio', que considera bem conhecido sua origem "alude à pluralidade (os daimones ou acompanhantes etéreos dos gregos) e é quase sempre empregado nessa acepção.” (COUSTÉ,1996, p. 12).

Em outro momento, Cousté retoma a questão da nomenclatura referindo-se ao papa Paulo VI:

Depois de recordar que o dogma da existência do Diabo tinha sido claramente estabelecido pelo IV Concílio de Latrão (em 1215), o papa acrescentou; "Não se trata de um único demônio. Satanás, que quer dizer inimigo, é o principal, mas com ele há muitos outros, todos criaturas de Deus decaídas por sua rebeldia e condenadas. (idem, p. 278)

Também Arturo Graf, estudioso italiano da obra de Dante e da Idade Média, comenta a respeito dos nomes do diabo:

S. Tommaso, al pari di molti altri teologi, e conformemente a quanto è accennato nel Nuovo Testamento, ammette che fra i demonii come fra gli angeli rimasti fedeli, ci sieno varii ordini e una gerarchia, a capo della quale è Beelzebub. Dante

\footnotetext{
* Maria Teresa Arrigoni é Doutora em Linguística pela Unicamp e Prof ${ }^{a}$ Titular aposentada da Universidade Federal de Santa Catarina (UFSC).
} 
non esprime a tale riguardo una opinione categorica; ma presenta Lucifero quale re dell'Inferno e principe dei demonii, cui forse Plutone invoca nel suo inintelligibile linguaggio. Quanto agli altri demonii si può notare qua e là qualche indizio di primazia e di soggezione. ${ }^{19}$ (GRAF, 2002, p. 282)

Diante da diversificação de nomenclatura, que já mereceu extensas pesquisas, optei por me utilizar de diferentes acepções ao longo da busca pelo diabo no Inferno de Dante: os demônios serão aqueles que vindos da mitologia ocupam quase sempre a função de guardar este ou aquele círculo; os diabos serão aqueles que mais se ocuparão de torturar os pecadores e Lúcifer estará no final da viagem, no lugar mais profundo do inferno.

A primeira idéia que se pode ter do Inferno da Divina Comédia é de que vamos nos defrontar logo de início com uma multidão de diabos, aqueles seres negros, munidos de chifres, asas de morcego e cauda com ferrão que as ilustrações inculcaram na nossa imaginação ocidental.

No entanto, o primeiro contato de Dante - e aqui me refiro ao personagem que realiza a travessia - com o reino da punição se dá no silêncio e na presença de seu guia Virgílio. Trata-se do momento em que o viajante lê as palavras tenebrosas que estão esculpidas na pedra da porta. A porta do inferno dantesco não está fechada e não se mostra guardada por ninguém. Somente aquela inscrição que a apresenta 'fala', deixando bem claro no final o conhecido verso: Lasciate ogne speranza voi ch'intrate (III, 9) ${ }^{20}$. Aqui já se pode perceber uma carac-

19 "São Tomás, juntamente com muitos outros teólogos, e conforme o que está dito no Novo Testamento, admite que entre os demônios assim como entre os anjos que permaneceram fiéis existem várias ordens e uma hierarquia, e que seu chefe é Belzebu. Dante não expressa uma opinião categórica a esse respeito, mas apresenta Lúcifer como 'rei do Inferno' e 'príncipe dos demônios', a quem talvez Pluto invoque com sua linguagem ininteligível. Quanto aos outros demônios, podem-se notar aqui e ali alguns indícios de superioridade e de submissão." (Tradução minha deste e dos demais textos críticos em italiano).

20 Utilizo nas citações em italiano a Divina Commedia de Pasquini \& Quaglio. Torino, Garzanti, 1998, vol. I. Indicarei entre parênteses o canto do Inferno e o/os verso/s citados. A tradução de Cristiano Martins, nas notas, será extraída do volume indicado na bibliografia. "Por mim se va à cidadela ardente/por mim se vai à sempiterna dor,/por mim se vai à condenada gente./Só justiça moveu o meu autor;/sou obra dos poderes celestiais,/da suma sapiência e primo amor./Antes de mim não foi coisa jamais/ criada senão eterna, e, eterna, duro./ Deixai toda esperança, vós que entrais" (p. 97). 
terística muito importante desse inferno que Dante percorrerá - e nós com ele: o inferno é o reino da ausência absoluta da esperança. Da eterna ausência da esperança, se considerarmos as palavras que antecedem o verso citado:

\author{
"Per per si va ne la città dolente, \\ per me si va ne l'etterno dolore, \\ per me si va tra la perduta gente. \\ Giustizia mosse il mio alto fattore; \\ fecemi la divina podestate, \\ la somma sapïenza e 'l primo amore. \\ Dinanzi a me non fuor cose create \\ se non etterne, e io etterno duro. \\ Lasciate ogne speranza, voi ch'intrate". (III, 1-9)
}

Podemos pensar na ausência da esperança de ver Deus, como principal causa do sofrimento eterno, mas também no fato de que não existirá retorno, de que não se poderá jamais reverter a inexorabilidade da sentença, além da existência interminável dos suplícios. É, pois, a porta, o elemento cênico que começa a provocar calafrios no nosso viajante que nessa città dolente, nesse reino da dor eterna vai caminhar com Virgílio. O estatuto infernal apresenta suas cláusulas. A elas voltaremos ao longo do percurso.

Se a porta se manifesta em seu silêncio tumular, após ter vencido o temor de perpassá-la, Dante se depara com outra característica: as trevas que o fazem perder a visão. Assim, costumo dizer que o primeiro encontro de Dante com o inferno é através da audição: gritos, blasfemas, choros e lamentos chegam a seus ouvidos antes mesmo que a visão possa discernir alguma coisa. Mais adiante será o olfato o sentido mais castigado com os miasmas fétidos do inferno.

Dante não vê diabos, e sim uma multidão que corre atrás de uma bandeira sem símbolo algum. Perseguidos e picados por vespas mutucas, estão lá homens e mulheres, todos nus, cujo sangue e suor, escorrendo ao longo dos corpos servem de alimento aos vermes que pululam no chão. Mais uma cláusula do inferno: o contrapasso, que faz com que a punição guarde com o pecado liames de analogia ou contraste. São os ignavos, aqueles che visser sanza 'infamia e sanza lodo (III, 36) ${ }^{21}$. Aqueles que nem o inferno quer, por não terem sido capazes de 'assumir' um pecado, por não terem tido a 'fibra' de participar da vida, inclusive pecando. Dentre aqueles que ali estão, Dante inclui $l i$ angeli che non furon ribelli/ né fur fedeli a Dio, ma per sé fuoro (III,

21 "transitaram/ sem merecer louvor ou execração" (p. 98). 
38-9) ${ }^{22}$, sem que no entanto tenham feições de diabos.

Às margens do primeiro dos rios infernais, o Aqueronte, Dante e Virgílio encontram o primeiro dos demônios infernais. Trata-se de Caronte, o antigo barqueiro da mitologia grega, retomado por Virgílio e outros poetas latinos, que agora transporta em sua barca as almas destinadas ao eterno castigo. Assim Dante o descreve como un vecchio, bianco per antico pelo (III, 83), com lanose gote (III, 97), um velho de barbas e cabelos brancos, com pelos que lhe cobrem as bochechas e os olhos injetados de vermelho na sua tarefa de incitar as almas a se apressarem para a travessia. Do rosto, sua característica mais marcante é retomada, os olhos cor de brasa:

Caron dimonio, con occhi di bragia

loro accenando, tutte le raccoglie;

batte col remo qualunque s'adagia, (III, 109$111)^{23}$

Uma vez superado o obstáculo do rio, mas antes de encontrar o segundo demônio, Dante percorre o Limbo, no qual estão as almas daqueles que não fizeram o mal, mas por não terem sido batizados não poderão ter a esperança de ver Deus, o que os faz suspirar eternamente. O silêncio desse círculo é, pois, quebrado pelos suspiros pungentes desses homens e mulheres, muitos deles pagãos, que sofrem o castigo dessa ausência. Em um outro espaço desse mesmo círculo Dante encontra num castelo os poetas gregos e latinos que o recebem como a um colega: Homero, Horácio, Ovídio e Lucano.

É no Limbo que Virgílio também 'mora', como o quinto dos grandes autores. Dante será o sexto, e ele somente está vivo. Eis a linhagem da qual o poeta demonstra ser o sucessor. Além dos poetas, encontram-se no castelo os sábios da Antigüidade: de Sócrates a Heráclito, de Platão a Avicena, de Aristóteles a Hipócrates. E a ausência de demônios dá ao círculo a sensação de uma aparente tranqüilidade, uma pausa em que as vozes não chegam ao ouvido, numa descrição que se assemelha a um daqueles afrescos que surgiriam mais tarde pelas mãos de Rafael.

É no segundo círculo, o dos luxuriosos, que se encontra o segundo demônio: Minós. Tirado da mitologia grega, assim como Caronte, e retomado na latina, Minós, rei e legislador de Creta, personifica o juiz e suafunçãó aparentemente a de julgar e principalmente a de designar 22 "dos anjos que não foram rebelados,/ nem fiéis a Deus, mas só em si cuidaram" (p. 98).

23 "O demônio Caronte, o olhar em brasa/ aos gritos os chamava e ia reunindo,/ dando co’a pá nalguns que o medo atrasa” (p. 101). 
a cada alma seu lugar no inferno. Sob o domínio do demônio Minós estão aqueles que pecaram carnalmente e Dante se comove com a história narrada por Francesca, açoitada pela eterna tempestade ao lado de seu cunhado e amado Paolo. As ilustrações apresentam minós como um ser gigantesco, meio homem meio animal, cuja cauda se envolve no pecador ou em si mesma pelo mesmo número do círculo para o qual foi destinado. A diversidade das figurações de Minós resulta, a meu ver, da ausência de detalhes na descrição que Dante nos fornece daquele que Pasquini denomina demoniaca macchina di giustizia ${ }^{24}$ :

Stavvi Minós orribilmente, e ringhia:

esamina le colpe ne l'intrata;

giudica e manda secondo ch'avvinghia. (V, 4-6) ${ }^{25}$

Temos que colher seus detalhes naquele orribilmente e no fato que sua voz é um ranger de dentes. Apesar da rudeza com que apostrofa Dante, querendo impedi-lo de continuar e astutamente tentando fazê-lo duvidar de Virgílio - e não é essa uma das prerrogativas dos demônios? - a fórmula que o mestre emprega não deixa dúvidas de que também esse demônio, que conhece os pecados e encaminha os pecadores está, como os outros, eternamente a serviço d'Aquele que, como já vimos nas linhas gravadas na pedra da porta, foi também o criador desse reino.

Continuando a descida, os viajantes se deparam com outro demônio: Cérbero, o cão infernal de três cabeças, presente em inúmeras ficções, desde a Eneida até a recente saga de Harry Potter. Cérbero guarda o círculo dos gulosos e com seu latido medonho e com suas garras mortais incrementa o sofrimento daqueles que lá são punidos, na lama fétida, por terem extrapolado no pecado da gula:

Cerbero, fiera crudele e diversa, con tre gole caninamente latra sovra la gente che quivi è sommersa.

Li occhi ha vermigli, la barba unta e atra, e 'l ventre largo, e unghiate le mani; graffia gli spirti ed iscoia ed isquarta. (VI 13-18) ${ }^{26}$

Além de exercer a função de guarda, Cérbero acresce a punição

24 PASQUINI, E. Op. Cit., 'Comentário ao canto V', p. 71.

25 "Dentes rilhando em fúria, ali se via/ Minós, que as culpas mede junto à entrada,/ pelas voltas na cauda, que fazia." (p. 110).

26 "Cérbero, dúplice animal, furioso, / com três gargantas ladra sobre a gente/ ali submersa, como cão raivoso./ Olhos em fogo tem, barba indecente,/ rotundo ventre, e mãos de unhas afiadas,/ com que esquarteja as almas, ferozmente." (p. 116). 
dos gulosos com suas garras com as quais arranha os pecadores até tirar sua pele e pedaços de seus 'corpos', já que aparecem aos olhos de Dante, como as outras almas, munidas da figuração corporal humana. De Cérbero temos alguns detalhes físicos, como os olhos em brasa presentes em muitas figurações, e nos hodiernos efeitos especiais - o ventre protuberante, retomando a bestialidade da gula, e as garras com as quais esquarteja os gulosos.

Também na entrada do quarto círculo, os viajantes encontram outro demônio: Pluto. Ele guarda os avarentos e os pródigos, punidos com um mesmo suplício: percorrer o círculo em duas fileiras distintas, empurrando pesadas pedras, num esforço inútil, que reproduz em eterno o inútil esforço terreno de juntar ou esbanjar riquezas. $\mathrm{Na}$ descrição que Dante faz desse demônio, o que mais chama a atenção e até hoje constitui um mistério para os comentaristas são as palavras que ele repete com uma voz rouca: Pape Satàn, pape Satàn aleppe (VI, 1), a respeito das quais já se fizeram inúmeras hipóteses - que estaria avisando Lúcifer é uma delas - sem que nenhuma tenha sido considerada resolutiva.

O fato de Virgílio mandá-lo calar-se, chamando-o de maladetto lupo! (VI, 8), faz com que em algumas ilustrações a Pluto também sejam dadas feições de cão feroz. Mas a maioria dos comentaristas retoma no feroz Pluto as mesmas características daquela loba magérrima, símbolo da cobiça, que impede Dante de subir o monte, querendo livrar-se da selva oscura (I, 2). Não temos propriamente uma descrição, mas sobressai sua voz chioccia (VII, 3), que mais do que rouca eu diria 'cavernosa'. A altura descomunal é apontada através da analogia com o mastro de um navio, ao descrever a caída por terra da criatura após ter sido colocada em seu lugar pelas firmes palavras do mestre Virgílio:

Quali dal vento le gonfiate vele caggiono avvolte, poi che l'alber fiacca, tal cadde a terra la fiera crudele. (VII, 13-15) ${ }^{27}$

E um demônio já presente na mitologia aparece quando Dante e Virgílio se aproximam do pântano Stige, o segundo rio infernal, no quinto círculo: é Flégias, barqueiro ele também, que vai transportar os dois até as muralhas de Dite. Costuma ser figurado no corpo de um velho, menos forte que Caronte, numa barca menos amedrontadora, mas personifica a ira dos pecadores imersos nas águas e na lama do

27 "Como as velas infladas do batel,/ que caem rotas, quando o mastro parte, assim tombou ao lado o monstro cruel" (p. 122). 
pântano, dos quais é guardião. Segundo Graf:

Il corpo di cui è provveduto il demonio Flegias è certo un corpo sottilissimo, non più pesante dell'aria entro a cui si muove, e in tutto simile all'ombra di Virgilio, giacché la barca con cui egli fa passare ai due poeti la palude degli iracondi sembra carca solo quando Dante vi entra. (Op. cit, p. 269) ${ }^{28}$

Se até esse ponto da viagem, todos os obstáculos colocados pelos demônios haviam sido superados pelo mestre Virgílio, dando a Dante uma sensação de segurança, a situação muda radicalmente diante dos diabos, aqueles più di mille (VIII, 82), que impedem aos viajantes a entrada pelo portão de Dite. E de nada servirão as tentativas de Virgílio de convencê-los a abrir passagem. Assim, a primeira multidão de diabos, cuja figuração costuma ser a mais conhecida: seres negros, dotados de chifres, asas de morcego, vai realmente constituir um obstáculo aparentemente intransponível e marca a passagem do alto para o baixo inferno; e já que no estatuto do inferno dantesco os pecados são mais graves à medida que se desce em direção ao centro da terra, passando as muralhas, deixam os pecadores da incontinência e encontram os da violência e os da malícia.

Da mesma forma que não há uma descrição detalhada dos seres citados, os versos de Dante não descrevem aqueles 'mais de mil diabos', a não ser como dal ciel piovuti (VIII, 83), aqueles que 'choveram do céu', na imagem de Dante, ou seja de lá foram precipitados por terem participado da rebelião. Sua característica principal é a tracotanza (VIII, 124), que pode ser traduzida por 'arrogância' e também como 'presunção', no sentido de que tentam se opor eternamente à vontade divina (Pasquini, 1998).

Enquanto não se resolve essa situação, outros seres demoníacos, retomados da mitologia grega, aparecem por cima das muralhas de Dite: as Erínias, ou Fúrias, Megera, Aleto e Tesífone, que convocam a mais conhecida das Górgones, Medusa - companheira mitológica de Euríale e Esteno:

ver' l'altra torre a la cima rovente, dove in un punto furon dritte ratto tre furie infernal di sangue tinte, che membra feminine avieno e atto,

28 "O corpo do demônio Flégias é por certo levíssimo, e não mais pesado que o ar que o envolve, em tudo parecido à sombra de Virgílio, já que a barca com a qual ele atravessa os dois poetas pelo pântano dos irados parece 'estar carregada' somente quando Dante nela entra." 
e con idre verdissime eran cinte;

serpentelli e ceraste avien per crine,

onde le fiere tempie erano avvinte. (IX, 36-42) ${ }^{29}$

E tanto as Fúrias como Medusa mantêm aqui suas características: enlouquecer as primeiras, petrificar a segunda. Tanto que Virgílio alerta Dante para desviar o olhar e para certificar-se disso, põe-lhe as mãos sobre os olhos. Cria-se, pois, um impasse que será resolvido a partir da presença de um messo celeste (IX, 85 e seg.), o mensageiro divino, figurado como um anjo, o qual munido de uma vareta - varinha? - faz com que todos os diabos se calem e os portões se abram.

Esse momento é considerado crucial na viagem e é explicado alegoricamente pelo impasse em vida do pecador. Este busca se livrar do pecado e se depara com as tentações, que dificultam - os diabos, o rememorar das culpas, que enlouquece - as Fúrias e o desespero que petrifica - a Medusa. Forças demoníacas que podem pôr a perder uma viagem a caminho da salvação. E que precisam de uma intervenção divina que, assim como na viagem dantesca, faz toda a diferença.

O sétimo círculo, que pune diversas modalidades de violência, tem como seu guardião outro ser mitológico, o Minotauro, em sua dimensão demoníaca. É descrito por Dante:

e 'n sul a punta de la rotta lacca

l'infamia di Creti era distesa

che fu concetta ne la falsa vacca;

e quando vide noi, sé stesso morse,

sí come quei cui l'ira dentro fiacca. (XII, 11-15) ) $^{30}$

Do aspecto físico do Minotauro - que por vezes se encontra retratado como um homem com cabeça de touro, outras, um touro com cabeça humana - Dante não fala. Isto ocorre, talvez por ser um monstro presente no imaginário ocidental, e o poeta limita-se a descrever sua violência - corcoveando - ao ouvir as palavras de Virgílio que lhe relembram a derrota sofrida no labirinto.

Na primeira divisão do sétimo círculo são punidos os violentos contra o próximo, mergulhados no sangue fervente do rio Flegetonte,

29 "Em contemplar o torreão candente,/ onde, súbito, notei que se alteavam/ três fúrias infernais, de sangue tintas,/que aspecto e forma de mulher mostravam./ Hidras verdes ornavam-lhes as cintas,/ e na cabeça cada uma trazia/ um nó de serpes, pérfidas, famintas." (p. 136).

30 "e à orla daquele abismo, sobreerguida,/ eu vi de Creta a infâmia inominada,/ numa vaca postiça concebida;/ ao divisar-nos, em si mesma o dente/ cravou, presa de fúria desmedida." (p. 153). 
o terceiro dos rios infernais. Além disso, os pecadores são guardados de perto pelos centauros, munidos de seus arcos, e prontos a flechar os pecadores que tentam de alguma forma aliviar o próprio tormento, expondo partes de seu corpo fora das águas 'quenterubras'. Nem todos os comentaristas estão de acordo que os centauros exerçam a dupla função de guardiões e torturadores, acrescendo o contrapasso daqueles que se mancharam com o sangue de suas vítimas. Diferentemente de Graf, que os coloca entre os demônios mitológicos, Pasquini considera mais o aspecto nitidamente guerreiro que eles assumem, em consonância com os exércitos e bandos dos tiranos, homicidas e predadores. O mesmo se pode dizer de Sermonti ${ }^{31}$, que os considera miliziani quadrupedi:

e tra ' 1 pie de la ripa ed essa, in traccia corrien centauri armati di saette, come solien nel mondo andare a caccia. (XII, 5557)

(...)

Dintorno al fosso vanno a mille a mille, saettando qual anima si svelle del sangue più che sua colpa sortille. (XII, 73$75)^{32}$

Continuando no sétimo círculo, na segunda divisão são punidos os suicidas e os dissipadores dos próprios bens, em duas modalidades diferentes de suplícios. Os primeiros são confinados em troncos de árvores e perdem a formatação do corpo humano por terem sido violentos contra si mesmos. Sua pena, como acontece em outros círculos, é exacerbada pelas Harpias, como demônios que despedaçam os galhos das árvores e se alimentam de suas folhas, causando dores às almas que lá estão confinadas. Os outros, os dissipadores, correm soltos por entre os arbustos e árvores, mas têm como suplício a perseguição das cadelas negras, que os estraçalham quando conseguem alcançá-los. Assim, mesmo sofrendo penas diferentes, as duas categorias de pecadores têm por característica perderem seus 'corpos', uns em função do suicídio, os outros pela dissipação dos bens.

As Harpias, apesar de manterem suas características mitológicas, são descritas nos versos dantescos, num primeiro momento em seu aspecto físico, depois em sua função de aumentar o tormento dos sui31 SERMONTI, Vittorio. L'Inferno di Dante, p. 224.

32 "Na praia, entre o fraguedo e a ampla abertura,/ um a um, os Centauros desfilavam,/ com setas, como quem caça procura." (p. 155). "São milhares, que afluindo, lado a lado,/ alvejam os que à tona vão subindo/ mais do que lhes faculta o seu pecado." (p. 156). 
cidas:

\author{
Ali hanno late, e colli e visi umani, \\ piè con artigli, e pennuto 'l gran ventre; \\ fanno lamenti in su li alberi strani. (XIII, 13-15) \\ (...) \\ l'Arpie, pascendo poi de le sue foglie, \\ fanno dolore, e al dolor fenestra. (XIII, 101-2) (33 $^{33}$
}

Esta última é a descrição do próprio suplício feita por uma das almas aprisionada no tronco, a de Pier della Vigna. Já a narrativa que trata dos outros pecadores desse mesmo lugar, que inutilmente tentam fugir à própria pena, encontra-se alguns versos à frente:

Di rietro a loro era la selva piena di nere cagne, bramose e correnti come veltri ch'uscisser di catena. In quel che s'appiattò miser li denti, e quel dilaceraro brano a brano; poi sen portar quelle membra dolenti. (XIII, 1249) 34

Nos comentários que percorri, existe coincidência em descrever as cadelas negras como elementos dinâmicos que se contrapõem às praticamente estáticas Harpias: o feminino alado e feroz. Não podemos deixar de lembrar que o diabo em forma de cão negro pertence ao zoomorfismo das visões dos anacoretas e as cenas de caça fazem parte do imaginário medieval, com seu misto de ritual e assassinato.

O próximo demônio a aparecer diante de Dante é o que guarda o círculo oitavo, chamado de Malebolge, as fossas do mal. Nesse círculo, subdividido em dez cavidades, são punidos os pecadores que usaram o agravante da malícia para praticar o mal. Gerião, um ser fantástico, em parte tirado da mitologia - o cruel rei morto por Hércules - e em parte saído da imaginação do autor, aparece vindo do fundo de um precipício, após ter sido convocado, misteriosamente, por Virgílio, que lhe ordena de levá-los ao fundo do abismo. Dante assim o descreve:

La faccia sua era faccia d'uom giusto, tanto benigna avea di fuor la pelle, e d'un serpente tutto l'altro fusto;

33 "De asas largas, cabeça e rosto humanos,/ rudes garras aos pés, ventre emplumado,/ de dentre as ramas, recontavam danos." (p. 160).(...) "pascendo em suas folhas, fere-o a Harpia,/ e da ferida grita, doloroso." (p. 164).

34 "Um pouco atrás, no bosque se espalhando,/ vinham surgindo cães, feros, ardentes, como rafeiros as prisões deixando./ No que parou foram metendo os dentes,/ dilacerando-o, fibra a fibra, então;/ e partiram, co' os restos seus dolentes.” (p. 165-6). 
due branche avea pilose insin l'ascelle;

lo dosso e 'l petto e ambedue le coste

dipinti avea di nodi e di rottelle. (XVII, 10-15) ${ }^{35}$

Esse demônio gigantesco que preside as fossas do mal, resulta de um conjunto de elementos simbólicos, entrelaçando, nas palavras de Pasquini, forme animali tra loro irriducibili (uomo-leone-serpentescorpione), cioè mammiferi-rettili-aracnidi ${ }^{36}$, de modo a abarcar toda a ambigüidade da fraude que Gerião representa. A honestidade que esconde a malícia, e os animais peçonhentos ou considerados ardilosos que compõem o seu corpo, somados aos arabescos multicoloridos que o percorrem, criam aquele fascino equivoco de que nos fala Sermonti:

dobbiamo registrare come il suo fascino equivoco non trasudi soltanto dalla finta onestà del viso, ma anche dalla bellezza autentica del corpo: insomma, come la frode, moralmente proditoria, irradi un sontuoso potenziale di seduzione, per non dire: il fascino dell'ambigüità. (SERMONTI, 2003, p. 311$)^{37}$

Terminada a viagem, em descida espiralada, os dois viajantes se encontram no emaranhado de passagens e pontes que vão percorrer por sobre as fossas. Na primeira, vêem os diabos - dotados de chifres e com chicotes - que são descritos enquanto perseguem e chicoteiam os rufiões e sedutores:

Di qua, di là, su per lo sasso tetro

vidi demon cornuti con gran ferze,

che li battien crudelmente di retro. (XVIII, 34$36)^{38}$

Na quinta fossa ${ }^{39}$, mergulhados no piche fervente e borbulhante,

35 "Era o seu rosto como o do homem justo,/ qual benigno, por fora se apresenta,/ mas da víbora tendo o corpo angusto./ Peludas asas desde a axila ostenta,/ e pintados mostrava o peito e as costas,/ em que de manchas um mosaico assenta." (p. 189-90)

36 PASQUINI, E. Op. Cit. p. 193. "Formas animais irredutíveis entre si (homem-leãoserpente-escorpião), ou seja, mamíferos-répteis-aracnídeos."

37 "É preciso registrar que seu fascínio equívoco não transparece somente da falsa honestidade do rosto, mas também da beleza autêntica do corpo: em suma, como a fraude, moralmente traiçoeira, irradia um luxuoso potencial de sedução, para não dizer: o fascínio da ambigüidade."

38 "Aqui e ali, na arena diferente,/ vi corníferos demos, estalando/ o relho em suas costas, rijamente." (p. 197).

39 Nas fossas seguintes onde são punidos os aduladores, os simoníacos e os adivinhos, não há a presença explícita de diabos. 
são punidos os corruptos e, mais especificamente, aqueles que prevaricaram, cometeram crime de peculato, fraudaram os cofres públicos. Nesse ponto da viagem acontece o encontro com os diabos que em parte se reveste de um caráter de farsa, em parte de perigo real para $o$ viajante em carne e osso.

É onde Dante encontra o que costumo chamar de a 'gang' dos diabos. Com chefe e tudo. Os Malebranche, ou 'garras do mal', são os diabos descritos e citados com seus nomes e têm a função de fisgar com seus ganchos os corruptos que tentam a todo o momento fugir do suplício do piche fervente. Seu chefe é Malacoda, 'cauda do mal', e os demais membros são: Scarmiglione, o que ataca e transtorna, o tumultuador; Alichino, cujo nome parece vir de Hallequin, personagem diabólico na lenda medieval da caçada feroz; Calcabrina, nome que pode ter vindo do fato de andar pisando sem fazer barulho; Cagnazzo, ou grande cão feroz; Barbariccia, aquele com os cabelos e barba eriçados como as chamas; Libicocco, nome que pode ter sido formado pelos ventos libeccio e scirocco, os ventos quentes e úmidos; Draghignazzo, nome alusivo a dragão; Ciriatto, cujo nome tem ligação com ciros, porco selvagem, e é, de fato, descrito como portador de presas grandes; Graffiacane, aquele que arranha, o cão que fere com as garras; Farfarello, com possível origem em farfanicchio, diabrete; e, por fim, Rubicante: o vermelho, ou o irado. São eles os protagonistas de dois cantos (XXI e XXII) e de uma agitada performance infernal.

Segundo Graf, é possível fazer-se uma conexão entre os nomes que Dante concede aos diabos e as peças medievais dos Mistérios e das Sacras representações:

I nomi che Dante dà a que' suoi demonii rimandano a Misteri e a Sacre Rappresentazioni, dove nomi consimili occorrono frequenti. Tali Misteri e tali Sacre Rappresentazioni sono, gli è vero, posteriori alla Divina Commedia; ma nulla vieta di credere che essi occorressero già in drammi più antichi, non pervenuti sino a noi. (GRAF, 2002, p. $291)^{40}$

Como se desenrola essa verdadeira farsa teatral? No momento

40 "Os nomes que Dante dá àqueles seus demônios remetem aos Mistérios e Sacras representações, nos quais nomes semelhantes ocorrem com freqüência. É verdade que esses Mistérios e Sacras representações são posteriores à Divina Comédia, mas nada impede que pensemos que já pudessem estar presentes em peças mais antigas, que não chegaram até nós." 
em que um dos corruptos, o tal de Ciampolo de Navarra consegue sair da fossa de piche, os diabos correm em sua direção para espetá-lo com seus ganchos. Ele, no entanto, convence-os de que poderia chamar para fora outros comparsas e assim os diabos poderiam se divertir também com os outros e teriam mais prazer em atormentá-los. Os diabos ficam por alguns instantes indecisos, brigando entre si, e quando dois deles resolvem correr para pegar Ciampolo, este mergulha no piche e não se deixa alcançar por eles. Furiosos os dois se acusam mutuamente e, na tentativa de fincar os arpões no dorso de Ciampolo, engalfinhamse no ar, com seus ganchos e suas asas emaranhados, acabando por despencar no piche.

Graf chama a atenção para as lendas e peças populares em que o diabo faz papel de bobo e passa por ingênuo, enganado, aludindo à questão da presença de certa 'comicidade', de demonio burlesco. Mas ao mesmo tempo, como um saldo moral, o que se vê nesse episódio de intensa movimentação é a capacidade do corrupto de enganar inclusive os diabos com sua malícia, típica comprovação do mau uso da inteligência que rege os pecados das Malebolge.

A carga de comicidade e de agitação do canto se transforma numa situação de tensão, do momento em que os diabos voltam sua atenção para os dois viajantes, querendo talvez vingar neles a própria frustração. Não é o caso de ficar para ver o desenlace: Dante e Virgílio passam rapidamente para a fossa inferior, onde são punidos os hipócritas, sem a presença de diabos, embora ao falar com frei Catalano Virgílio perceba que foi enganado por Malacoda: o diabo mentiu ao dizer que uma ponte estava caída. E a ironia do frade colhe Virgílio de surpresa:

E 'l frate: "Io udi' già dire a Bologna

del diavolo vizi assai, tra' quali udi'

ch'elli è bugiardo e padre di menzogna". (XXIII, $42-44)^{41}$

Considerando que Bolonha é nomeada por sua universidade uma das primeiras da Europa - percebe-se como as palavras do frei ironizam o enganado por desconhecer a lábia do enganador.

Na fossa seguinte à dos hipócritas Dante e Virgílio presenciam uma quantidade incontável de serpentes de vários tamanhos, até com pequenas asas, como dragões, lagartos, e toda espécie de seres rastejantes e venenosos. Embora não haja uma entidade diabólica única, não podemos deixar de pensar, com Cousté que "do ponto de vista 41 "E o frade, então: "Já em Bolonha ouvira/ os vícios decantar dos renegados,/ impostores e maus, pais da mentira." (p. 237). 
teológico e cosmogônico, a proto-encarnação do Diabo é a serpente ou - mais poderoso e mitológico ainda - o dragão, que é sua variante emblemática (Op. cit., p. 82). Assim, ao presenciarem os tormentos infligidos aos ladrões, se dão conta das dolorosas metamorfoses por que passam, 'como se fossem de cera quente', sendo ou incinerados ou continuamente roubados em sua forma humana pelas serpentes. Esse canto das metamorfoses é plasticamente único na obra de Dante e não foi por acaso que Machado de Assis o escolheu para sua tradução (O Globo, 1874). Reproduzir aqui toda a precisão das imagens que os versos de Dante constróem não será possível, mas segue a descrição de uma dessas cenas que ao mesmo tempo aterrorizaram e surpreenderam Dante, em que pecador e serpente vão amalgamando os corpos até que um se aproprie totalmente do corpo do outro:
Insieme si rispuosero a tai norme, che ' 1 serpente la coda in forca fesse, e 'l feruto ristrinse insieme l'orme. Le gambe con le cosce seco stesse s'appicar sí, che ' $n$ poco la giuntura non facea segno alcun che si paresse. (XXV, 103- 108)
(...)
e la lingua, ch'avea unita e presta prima a parlar, si fende, e la forcuta ne l'altro si richiude; e 'l fummo resta. (XXV, 133- $35)^{42}$

Assim nos descreve Dante o homem que cai ao chão, já sem membros, ora serpente/ cobra, ora humana, que sai a caminhar. Ainda a respeito da serpente, afirma Papini que: "é também o único animal que pode formar por si mesmo um círculo, que pode conformar e encerrar a superfície do mundo dentro de um limite, que é precisamente aquilo que a inteligência faz." ${ }^{33}$.

Continuando nossa descida, e deixando para outro momento o encontro com Ulisses, um dos episódios mais conhecidos e comentados da Comédia, o diabo reaparece, de forma indireta, no canto XXVII, quando os viajantes encontram a alma de Guido de Montefeltro, que conta sua história: a causa de se encontrar entre os maus conselheiros

42 "Intercambiaram-se ambos, claramente:/ os pés ia estreitando o condenado,/ e se fendia a cauda da serpente./ As pernas justapostas, lado a lado,/ se soldaram tão firmes, que à juntura/ vestígio algum podia ser notado./ (...) De um a língua unida ia-se abrindo, / porém a da outra, que era bipartida,/ se entrecerrava, o fumo suprimindo." (p. 250-51). 43 Apud COUSTÉ; A. Op. Cit., 82. 
(assim como Ulisses por causa de sua participação à trama do cavalo contra Tróia) e de como se deu o contraste entre São Francisco e o diabo. Guido havia sido um homem de armas, havia tido momentos de conflito com Roma, mas depois de uma reconciliação religiosa havia se tornado franciscano. Em decorrência disso, por ocasião de sua morte, São Francisco reivindicou sua alma para levá-la consigo ao Paraíso, mas se interpõe a sua ação o 'negro querubim', que começa a articular o seu discurso:

Francesco venne poi, com' io fu' morto, per me; ma un de' neri cherubini li disse: "Non portar; non mi far torto. Venir se ne dee giù tra' miei meschini perché diede 'l consiglio frodolente, dal quale in qua stato li sono a' crini; ch'assolver non si può chi non si pente, né pentere e volere insieme puossi per la contradizion che nol consente" (XXVII, 112$20)^{44}$

E o diabo continua a relatar a São Francisco, como numa peça teatral, de que modo o pecador se deixou enganar pelo papa Bonifácio VIII, que em troca da remissão dos pecados de Guido quis saber dele a maneira de romper as defesas de um inimigo seu que não havia conseguido derrotar. Assim o diabo argumenta que não é possível 'cometer o ato e dele arrepender-se ao mesmo tempo', por ser 'uma contradição'. E surpreende Guido ao levá-lo ao inferno:

Oh me dolente! come mi riscossi quando mi prese dicendomi: "Forse tu non pensavi ch'io löico fossi!" (XXVII, 121$23)^{45}$

Na verdade, Guido confiou na falsa absolvição do papa e ficou tranqüilo, e foi isso que o diabo, na sua esperteza, apontou: a falta de arrependimento, que configura a morte no pecado. Com essa demons44 "Quando Francisco, ao meu final alento,/ foi minha alma buscar, penalizado,/ um anjo mau bradou-lhe: - Eia, um momento!/ Este é meu, e não pode ser levado!/ Dês que o conselho deu, indignamente,/ seguro o trago à unha, bem fisgado!/ Só se perdoa a quem remorso sente./ E ser contrito e o mal ir praticando,/ pela contradição não se consente." (p. 265-66).

45 "Ai de mim! De pavor fiquei chorando,/ quando me ergueu e disse: - Quem diria/ que eu fosse com tal lógica arrazoando!" (p. 266). 
tração de lógica, o diabo conseguiu levar Guido para o inferno. No comentário de Graf, aqui parece que Dante autor se esqueceu do estatuto infernal no que concerne às almas destinadas ao inferno, ou seja, que se reúnem todas à margem do rio Aqueronte, para atravessá-lo na barca de Caronte. Nesse caso, parece que as crenças de seu tempo falaram mais alto que a reprodução do mito, presente também em Virgílio.

Prosseguindo a viagem, na nona fossa os diabos estão presentes: mutilam com espadas pontiagudas os pecadores punidos por terem sido fomentadores de discórdia ou terem propiciado algum cisma (ali se encontram Maomé e Ali). Membros são cortados, vísceras saem de feridas abertas e no clímax da narrativa, Bertrand de Born conversa com os viajantes segurando com o braço sua cabeça decapitada.

$\mathrm{Na}$ última das fossas, a décima, são punidos os falsários, os alquimistas, os mentirosos, todos eles vítimas de doenças que deixam alguns quase imobilizados, a outros causam acessos de raiva incontrolável, mas brigam entre si, sem que os diabos intervenham ou mesmo se mostrem por ali.

Continuando a descida, um outro obstáculo se apresenta na forma de um poço profundo ocupado pelos gigantes acorrentados. Não se configuram, propriamente como entidades demoníacas, mas representam a punição da soberba e da força bruta. E de certa forma a ligação gigante-demônio estava presente no imaginário medieval, como aponta Graf:

Demonii appunto erano, secondo un'antica opinione, i giganti nati dal commercio degli angeli e delle figlie degli uomini; giganti nerissimi trova Carlo il Grosso nell'Inferno da lui veduto, intesi ad accendere ogni maniera di fuochi; nelle Chansons de geste, i giganti sono spesso considerati come diavoli venuti fuor dall'Inferno, o come figli di diavoli. (Op. Cit., p 267) ${ }^{46}$.

De qualquer modo, eles estão acorrentados - menos Anteu - e remetem à mitológica vitória de Zeus contra os Titãs. Dentre os gigantes, o mais conhecido é Nembrot, que aparece em Gênesis, no episódio da Torre de Babel e, de fato, é reconhecido na sua fala que, incompre46 Demônios eram, segundo uma antiga crença, os gigantes nascidos do comércio dos anjos e das filhas dos homens; gigantes nigérrimos encontra Carlos, o Grande, no Inferno visto por ele, e estavam entretidos em acender todo tipo de fogos; nas Canções de Gesta, os gigantes são freqüentemente considerados diabos saídos do Inferno, ou como filhos de diabos. 
ensível, reproduz a confusão das línguas:

"Raphèl maí amècche zabí almi", cominciò a gridar la fiera bocca, cui non si convenia piú dolci salmi. $(X X X I, 67)^{47}$

Finalmente, depois de terem sido transportados ao último círculo do Inferno pela mão do gigante Anteu, Vírgilio e Dante encontramse nas águas congeladas do último rio infernal, o Cocito. No gelo, são punidos os traidores, considerados os piores pecadores, pois com a utilização da inteligência para o mal, fraudam as pessoas com quem têm uma relação de confiança ou proximidade. Esses pecadores encontram-se presos no gelo em maior ou menor proporção, de acordo com a zona do círculo em que se encontram.

E aqui novamente, apesar de Dante não enxergar nenhum demônio, os pecadores os tornam presentes ao contarem suas histórias. É o caso de frei Alberigo, que segundo se contava, fingiu fazer as pazes com dois parentes, e para tal convidou-os a sua casa; findo o almoço, no entanto, fez seus servos consumarem a cilada, assassinando-os. E esse personagem conta a Dante que tão logo fez o ato da traição, sua alma foi para o inferno e o diabo ocupou seu corpo na terra, continuando a regê-lo em seu quotidiano:

sappie che, tosto che l'anima trade, come fec'io, il corpo suo l'è tolto da un demonio, che poscia il governa mentre che 'l tempo suo tutto sia vòlto. Ella ruina in sí fatta cisterna; e forse pare ancor lo corpo suso de l'ombra che di qua dietro mi verna. (XXXIII, $129-35)^{48}$

$\mathrm{O}$ mesmo acontece com outro personagem do qual fala o frei: o genovês Branca Doria, cuja alma Dante não acredita que possa estar presa no gelo do Cocito, pois não lhe resulta a morte daquele que mangia e bee e dorme e veste panni (XXXIII, 141), come, bebe, dorme e se veste, continua aparentemente vivendo no mundo terreno.

47 "Raphèl maí amech zábi almos/ - grasnou, então, abrindo a boca aflita,/ sem poder modular mais doces salmos." (p. 293).

48 "sabe que quando um trai, incontinenti/ pode um demônio por ali se achando/ no corpo entrar-lhe, que, pois, o tolera, e até à morte irá movimentando./ A alma recai nesta cisterna fera;/ talvez esteja lá o corpo a andar/ deste que ao lado vês, e desespera.” (p. 313) 
O que hoje os efeitos especiais banalizaram já estava presente nas experiências assustadoras relatadas nas narrativas dos anacoretas, $\mathrm{e}$ posteriormente nas reflexões medievais, inclusive de São Tomás, como afirma Cousté:

Vários séculos depois o eminente São Tomás de Aquino aduziria uma nova complicação: para ele, os demônios não possuem um corpo material, mas podem apropriar-se do de homens e mulheres vivos. Outros autores menos ilustres propagaram também o rumor de que os demônios não tinham o poder de tomar conta do corpo de um ser vivo, mas que podiam, sim, fazê-lo com um cadáver recente; outros ainda acham que eles preferem os corpos em decomposição, e daí o hediondo e repulsivo de seu aspecto. (Op. Cit, p. 34)

E de certa forma, retomando essa tradição, Graf se refere à possibilidade do diabo que toma conta dos corpos quando diz que "il demonio può invadere il corpo umano e produrre in esso turbazioni simili a quelle che arrecano certi morbi; può inoltre animare i corpi morti e dar loro tutte le apparenze e gli atti della vita.” 49 (Op. Cit., p. 279)

Dante autor não nos poupa demônios e Dante personagem não pode deixar de se horrorizar a todo o momento ao longo de sua viagem pelo castigo eterno daqueles que são destinados ao inferno. Mas a viagem infernal está chegando ao fim, e no gelo está fincado Lúcifer, que aparece de longe como um enorme moinho de vento, pois o mover-se de suas asas de morcego lembra o moto de gigantescas pás, par di lungi um molin che '1 vento gira (XXXIV, 6). Lúcifer, lo 'mperador del doloroso regno (id., 28), que aparece colossal, se comparado aos gigantes, provoca em Dante uma reflexão que remete ao seu anterior status de Serafim:

S'el fu si bel com' elli è ora brutto,

e contra 'l suo fattore alzò le ciglia, ben dee da lui procedere ogne lutto. (XXXIV, 34$36)^{50}$

Esse terceto por si só mereceria considerações à parte porque nosso autor em seu magistral sintetismo aí colocou três questões que

49 O diabo pode invadir o corpo humano e produzir nele os incômodos similares aos de algumas doenças; pode, além disso, animar os corpos mortos e dar a eles todas as aparências e os sinais da vida.

50 "Se foi tão belo quanto agora é hirsuto,/ e se contra o Criador se ergueu, furente,/ é natural que engedre a dor, o luto." (p. 316). 
a Teologia ainda discute e a Teopoética reencontra em seu caminho. Em primeiro lugar, a questão da queda dos anjos, com Lúcifer à frente; em segundo, o tipo de pecado cometido, com ênfase à soberba, e, em decorrência disso, o fato que dele, Lúcifer, deve proceder todo o mal, o que nos levaria a percorrer outros labirintos. Mais seguro neste momento será enfatizar, seguindo o exemplo dos comentaristas, o primeiro dos pensamentos de Dante na presença do monstruoso imperador do inferno, e repensá-lo, como faz Papini: Dante, dunque, è dominato dalle immagini di ció che Lucífero fu in principio più che dalla sua spaventosa figura presente: pensa alla sua stupenda bellezza, alla nobiltà della sua prima natura, alla sua superiorità sopra tutti gli altri esseri creati. ${ }^{51}$ (PAPINI, 1954, p. 300)

Poderíamos também pensar por um segundo, seguindo outros preceitos, na possibilidade de Lúcifer vir a ser 'perdoado' no final dos tempos. Mas isso romperia com a estrutura já exposta nos dizeres da porta: o inferno e tudo e todos os que o habitam estão sob a insígnia da eternidade. E Dante será lembrado por muitos condenados ao longo do percurso infernal que após o Juízo Final muitas das penas serão exacerbadas, sem vislumbre de perdão.

Retomando, sob outro aspecto, os dizeres da porta, pode-se perceber que na antítese das três pessoas da Trindade lá nomeadas estão, presas em uma só cabeça, as três caras de Lúcifer: a da frente - vermelha - opõe o ódio ao divino amor do Espírito Santo; a da direita branco-amarela - símbolo da ignorância, se opõe à divina sabedoria do Filho e a da esquerda - negra - se opõe, representando a impotência, à divina potência do Pai. Às asas luminescentes e translúcidas, se opõem as seis asas de morcego, opacas e opressivas, naquele mecânico movimento congelante.

Três traidores terminam as noites de sua "segunda morte" eternamente mastigados nas bocas de Lúcifer: Judas, traidor de Cristo, da Igreja, na boca da frente, cumpre sua pena somente com parte do corpo para fora, esperneando sem cessar - faz lembrar os simoníacos da terceira fossa -, à mercê das garras afiadas que lhe arrancam a pele; Bruto e Cássio, traidores de César, e ,por extensão, do Império, nas outras duas bocas, com o tronco para fora e a parte inferior dentro das bocas que os mastigam.

51 "Dante, pois, mais do que pela sua figura presente, é dominado pelas imagens do que Lúcifer foi no início, e pensa em sua extraordinária beleza, à nobreza de sua primeira essência, a sua superioridade em relação a todos os outros seres criados." 
Mas Lúcifer, longe de emitir qualquer som diabólico, satanicamente chora, e esse pranto que mina de seus seis olhos escorre por seus três queixos e cai misturado à baba sangrenta:

Con sei occhi piangea, e per tre menti
gocciava 'l pianto e sanguinosa bava.
Da ogne bocca dirompea co' denti
un peccatore, a guisa di maciulla,
sí che tre ne facea sí dolenti. (XXXIV, 53-57)

O impacto dessa figura monstruosa e ao mesmo tempo impotente poria por si só um fim à visão fantástica do inferno, mas a razão personalizada no guia Virgílio diz a Dante que é hora de prosseguir. Mais uma humilhação para o pobre diabo! No emaranhado de pelos de seu corpo, os viajantes vão ter um suporte que lhe serve de escada e desse modo descem um tanto, até encontrarem, já do outro lado da terra o caminho subterrâneo que os levará ao Purgatório.

Nosso olhar e nossa imaginação que já presenciaram outros demônios, não podem deixar de passar por certa frustração pela quase imobilidade desse imperador sem fala e sem ação. Mas o que teria Lúcifer para falar, para fazer nesse momento? Não estaria guardando sua fala e sua perfomance para os séculos mais próximos de nós? Outros finais surgirão. $\mathrm{E}$ novamente haverá belzebus, demônios, satanases e diabos povoando de negro novas páginas, o que nenhuma inquisição poderá impedir.

De qualquer modo, é da viagem que Dante realizou que trata a Divina Comédia. E no âmbito dessa ficção que se faz verdade a cada nova leitura, podemos realmente afirmar e confirmar que lugar de diabo é no Inferno de Dante!

\section{Referências}

ALIGHIERI, Dante. Divina Commedia - Inferno. Notas e comentários de Emilio Pasquini e Antonio Quaglio. Torino: Garzanti, 1998, vol. I.

Divina Commedia - Inferno. Notas e comentários de Natalino Sapegno. Firenze: La Nuova Itália, 1986, vol. I.

52 "dos seis olhos um pranto permanente/ nascia e aos três queixos lhe tombava./ Em cada boca triturava a dente,/ como a espadela ao linho, um condenado;/ as três eu via simultaneamente". (p. 317). 
A Divina Comédia. Tradução de Cristiano Martins. Belo Horizonte-São Paulo: Itatiaia-EDUSP, 1976.

Cousté, Alberto. Biografia do diabo. Tradução de Luca Albuquerque. Rio de Janeiro: Record: Rosa dos Tempos, 1996.

GRAF, Arturo. "Demonologia dantesca". In: Miti, leggende e superstizioni de medio evo. Milano: Paravia Bruno Mondadori, 2002.

MESSADIÉ, Gerald. História Geral do Diabo. Tradução de Alda Sophie Vinga. Mem Martins: Europa-América, 2001.

PAPINI, Giovanni. Il Diavolo. Firenze: Vallecchi, 1954.

SERMONTI, Vittorio. L' Inferno di Dante. Milano: Rizzoli, 2003. 